\title{
From the Sameness to the Difference: New Citizens' Children Education Fairness Path
}

\author{
Jinxia Qiao \\ Qiongtai Normal University \\ Haikou, China
}

\begin{abstract}
In the process of searching the education equality of new citizen' children, education fair on starting point is mainly to solve the "to study ", which result from the management and control in macroscopic aspect of national policy, to realize the right of equality and unity of children in the urban and rural areas, highlight for the same. At present, the basic requirement has been realized, how to "go to school better" is main problem, embodied in the school and teachers specific attention in the education process, in the face of urban and rural culture and regional culture in different groups, to face up to the difference, highlighting their differences, have the differences as resources to promote the development of children, to promote the common development of all children.
\end{abstract}

Keywords-sameness; difference; new citizen' children; education fair

\section{INTRODUCTION}

The question of fair education has long existed in our country. The discussion on the education equity of New Citizens' children has been heating up since the 90s of last century. At present, the theory of fair education is mainly embodied in three aspects, that is, the educational starting point, the educational process and the educational result. In pursuit of the education equity of migrant workers' children, the three aspects cover different contents and tasks, that is, the starting point of education fairness is mainly to solve the "problem of having school to go", realize equality and unification of rights of children education in urban and rural areas, highlighting the same, mainly reflected in the macro management and regulation of national policy; education process fair is in the basic of equal rights, mainly to solve the "problem of having good education". In this process, the difference between urban and rural education, urban and rural culture and family background is the key factor to block the "good education". Therefore, facing the existence of differences, taking difference as an educational resource and carrying out differential education, we can make the children of migrant workers enjoy the fair in the process of education and realize the integration of education. At present, with the promulgation of a series of policies to protect migrant

Project supported by the Youth Academic key project of the education department of Heilongjiang province in 2014" A study on the education of new citizen's children"(NO.1254G042); Philosophy and social science program of Heilongjiang Province in 2014" Development of education mode of migrant workers' children under the background of educational informatization"(No. 14EO26) children, the "problem of having school to go" of most of the migrant children is basically solved, that is, the educational starting point has been basically fair, and the consistency and identity of the education right have been preliminarily realized. Then, it is necessary to shift the focus of attention to how to achieve fairness in the process of education, pay attention to how to promote the healthy development of different groups and individuals in the school environment. As mentioned above, the implementation of differentiated education, highlighting the differences is the key factor to realize the fairness of the educational process. Therefore, in the promotion of the level of educational equity, it is necessary to undergo the change of the connotation and the task, that is, the shift from emphasizing the same to emphasizing the difference.

\section{SEEKING THE SAME: THE EVOLUTION OF SCHOOL POLICY}

The issue of children's education has attracted wide attention in 1990s, the government's first policy document on the education of migrant children was in 1996. With the accelerated development of urbanization in China, the education of migrant children has become increasingly prominent, and the Chinese government has promulgated a series of policy documents. As of 2016, the issue of migrant children's education had attracted policy attention for 20 years. During the period, a series of related policies were introduced by the central government, and the policy framework was constructed. Throughout the 20 years, the Central Government's policy efforts on the education of migrant children have been designed to reduce the educational gap of migrant children and local children arising from the dual household registration system, thus achieving the ultimate goal of "equal treatment".

\section{A. The Gradual Improvement of Educational Rights and Interests}

After the 1990s, with the development of China's urbanization process, large-scale migrant workers moved in cities and their children's education problems caused scholars and government attention. Because of the existence of the dual household registration system, the educational rights and interests are closely linked with the household registration system, and the migrant children migrate from the township to the city, resulting in divestment of their 
household registration and educational public services. Facing with the influx of children, how to protect them enjoy the same educational rights and interests as urban children, become the main topic of government work. Since the mid1990s, our government has introduced a series of policy documents to reduce the educational differences between migrant and local urban children, and to ensure that they are "equal" in the education rights.

In the case of the educational rights and interests, the government issued "the school-age children enrollment for urban floating population (Trial)" in 1996, to ensure the migrant children can attend urban public schools, but they were transient student and paid some fees. According to the characteristics of the public welfare and popularity of compulsory education, this is actually a kind of differential treatment, and it directly increases the difficulty of the migrant children entering the city public schools. In 2001 the State Council made "on the basic education reform and development decision", proposed the "two oriented" policy, take a variety of forms, according to the law to protect migrant children receive compulsory education rights, to ensure the provisions of migrant children's education right, which has landmark significance. In 2003, the State Council forwarded the Ministry of education "on further improving migrant children compulsory education work opinions", pointed out that "to join the league, extracurricular activities, the school should treat the migrant children as the city students, and asked the government to ensure migrant children's fees as local students. For the first time migrant children education rights was granted by legal provisions, the "opinions" in two "equally", stressed state's clear attitude on migrant children about equal rights.

In 2006 the State Council issued the "opinions" on solving the problem of migrant workers, also pointed out that it is necessary to protect the migrant children equal access to compulsory education, and the city public schools treat migrant children to receive compulsory education as local students in charge, management and other aspects, and declared not to charge fees and other any expenses. In 2006 this provision was written into the law of compulsory education, require the local government provide equal access to compulsory education for the migrant children, ensure the migrant children really enjoy the same education rights as local students; the attitude of government in ensuring the migrant children education rights is becoming increasingly clear and bright. In 2010 the State Council approved the "national long-term education reform and development plan", on the stage of compulsory education for migrant children, put forward new requirements from promoting fair education level, formulate the method of the entrance examination after compulsory education, and further in protect the equal rights of migrant children's education level.

\section{B. The Way of Education by Transient Student to the Nearest School}

With the attention of various media and academic circles to the issue of migrant children's education, this problem has gradually aroused the concern of the national education administration. In 1995 the Ministry of education began investigating the problem of children of floating population, and on 1996 issued the "urban floating population of schoolage children enrollment measures (Trial)", in Beijing, Tianjin, Shanghai, Zhejiang and other 6 provinces elected by the 1 district trial, according to the trial results, in 1998 the Ministry of education, Ministry of Public Security jointly issued the "Interim Measures for migrant children education". From then on, the children's education began to be formally concerned by the national policy. In this way, all the migrant children mainly enroll into the full-time schools ", defined the migrant children in the city school is transient student and pay certain fees. Compared with the local children, migrant children not only to pay certain fees, but also comply with the relevant conditions to enter public schools. In 2001, the State Council promulgated the "the basic education reform and development decision", pointed out that the stage of compulsory education of migrant children in the city go to school "by local governments, and by public schools", did not mention transient student. In 2003, the special policy document on solving the compulsory education for migrant children-- the opinions on further compulsory education for migrant children was issued by the State Council. The opinion clearly pointed out public schools should receive the migrant children as much as possible, to protect migrant children receive compulsory education. With the migrant children was placed on compulsory education, means that enjoy the city public resources is the proper meaning of its title, migrant children should also treat as city children at enrollment and identity. In 2006, the newly revised Compulsory Education Law explicitly pointed out that local people's governments at all levels should ensure that school-age children and adolescents are enrolled in schools near their residence. At the same time also stressed that for the parents or other legal guardians in non-domicile or residence of school-age children and adolescents, their parents or other legal guardians work or residence to receive compulsory education, the local people's Government shall provide equal access to compulsory education conditions, from the level to ensure equal access to migrant children compulsory education rights legally.

In 2010, the "national program for medium and long term educational reform and development" reiterated the policy of "two primary enrollment ways" and ensured that the migrant children receive compulsory education equally. To implement the "national education plan", the following year, the Ministry of Education issued the "on the 2011 fall semester migrant children compulsory education work notice" require various provinces and cities before the opening, ensure the migrant children go to school "nearly" and "freely". Although just to ensure that migrant children meeting the requirements of local government should receive compulsory education equally, but it is still a breakthrough without household registration restrictions lose situation, to ensure the migrant children's admission to a certain extent.

\section{The Gradual Convergence of Charging Standards}

In accordance with the provisions of the compulsory education law, all the students during compulsory education enjoy the free tuition, that is to say, regardless of where go to 
school, all countries can enjoy such treatment, therefore, transient student should not pay tuition, the education funding should be extracted from the migrant population taxes and transferred to public schools accepting the transient student. However, at that time China did not have the relevant legal provisions, so that before the middle of $90 \mathrm{~s}$, the migrant children in city school are charged. According to the survey of migrant children who are not enrolled in school age, migrant children from rural areas have reached $66.7 \%$. The reason for not attending school is that the school fees are too high. In fact, since 90s a large number of school-age migrant children inflow into the city, bring greater running school and funding pressure on the government and public school, so the appropriate charge tuition is reasonable. In 1998 "migrant children school Interim Measure was issued", clearly defined migrant children was transient student, migrant children in public schools to charge some fees became behoove. Going to school is difficult and expensive, which has become a prominent problem for the migrant children.

After entering twenty-first Century, in order to change the development level of basic education, the state promulgated the "decision on the basic education reform and development" on 2001, the phenomenon of, clearly put forward to resolutely skid arbitrary charges and control the charging standards in some places and school, in order to effectively reduce the rural parents' burden, which suppress high tuition for migrant children to a certain extent. At the same time, in order to solve the problem of the compulsory education for the migrant children, the government has established the policy of "the management of the local government and the full-time public primary and secondary schools mainly". As a starting point, the country began to pay close attention to the education of the children of migrant workers, and introduced the safeguard clauses in their enrollment fees. On September 30, 2003, the State Council forwarded the Ministry of education "on further improving migrant children compulsory education work opinions", which pointed out: "the government should make migrant children receive compulsory education fees, relief related expenses, charge as local students". In 2006 the State Council promulgated the "opinions on solving the problem of migrant workers" clearly pointed out that to protect the migrant children equal access to compulsory education, bring the compulsory education of migrant children workers into the local education development plan, included in the education budget. At the same time, pointed out that the city public schools make no discrimination on charge management and other aspects as local students, not be allowed pay tuition and any other fees. Temporary schooling fees lasted for 10 years finally stopped. The same year, the newly revised "Compulsory Education Law", once again clearly stipulates the compulsory education as a public welfare undertaking, for all school-age children, "free tuition and fees". At this point, Migrant children have reached the same level of fees as local children. The newly revised "Compulsory Education Law" promulgated, some large and medium-sized city, such as Shanghai, Fuzhou, Xi'an and other places introduced he knew local policies of free tuition or tuition and sundry fees, which relive high expenditure of going to school.

Through the study of migrant children policy evolution, can be clearly seen that countries make efforts and exploration in the aspects of fair treatment and equality of educational opportunity, trying to narrow differences between the migrant and local children, and strive to reach convergence in the school fees, rights and interests. After entering twenty-first Century, the role and position of the country has also undergone a major conversion on migrant children, starting from the present problem to cause concern to the passive solution, to actively guide, to highlight gradually the equal opportunity of migrant children. In fact, as for equal education opportunity, which mainly refers to the people to accept public education opportunities, and as the main provider of public education, the government aims to provide equal educational opportunity for all children. With the continuous introduction of new policies for the protection of children's schooling, the migrant children in China have made remarkable achievements in public schools. As the institutional arrangements of these policies promulgated by the state, which ensure the possibility to certain qualified people to public education resources from the macro level, but did not abolish all the meso or micro education gap or education inequality, the migrant children's education problem has changed from "to go to school difficultly" to "quality worries" and "hard fusion" hidden. To promote and realize educational equality in full and complete sense is not only an educational action, but also a social action. From the above, the full realization of educational equality, not only depends on the national macro oriented policy, also depends on the various sectors of society especially in efforts on the elimination of education inequality by school. At present, the public schools have made great efforts in carrying out the policy of equal education opportunities for the migrant children. They have basically reached the same goal of sharing the right to enter school. Then, how to ensure the realization of the right to study and how to truly enjoy the equality of the educational process is an urgent problem to be solved. Urban and rural economic structure still exists, the difference between urban and rural education is difficult to solve, but also become a bottleneck restricting the education integration of migrant children. Therefore, it is necessary for schools and teachers face the differences, and to break the "quality worries" and "fusion difficulties" in the migrant children's education.

\section{RETAIN THE DIFFERENCES: THE DEMANDS OF URBAN AND RURAL DIFFERENCES}

As mentioned above, after more than 20 years of efforts on "seeking the same", migrant children are obtained entrance opportunity. However, differences between urban and rural areas, such as educational differences, cultural differences and family educational backgrounds, are the key factors that block their effective education. Because of many differences exist between urban and rural children; resulting in potential differences in development is an indisputable reality. For public schools and teachers, only give all the 
students equally treated, which not enough, must be aware of differences, to have "foreignness" attitudes and values.

First is the existence of educational differences. Our two social structure system between rural and city separately, resulted in the allocation of educational resources was outoff-balance, so that there is a significant difference between urban and rural school conditions, such as teachers, education investment. With the development of China's economy, the improvement of per capita GDP, which bring further widening the income gap between urban and rural areas, the gap between urban and rural education, bring opportunity inequality in the education conditions, educational content, learning achievement, which further widen the gap between urban and rural education. As noted by Michael Ruskin et al., poverty "fundamental issues deeper is their lack of formal education, it will produce the illiterate and innumerate labor". In the face of a huge gap between urban and rural education, with the dream of changing the face by education, more and more migrant workers send their children into the city to receive better education, so that the poverty cannot occur on the next generation. Education as individual factors in social mobility is increasingly important, the individual social status depends more on education. In a sense, migrant workers have experienced changes from rural to urban areas, and they feel deeper and more specific differences between urban and rural areas, so they have more profound expectations for their children. It can be said that the life experience makes them realize the importance of knowledge, and they want their children to receive better education, so as to translate into the chips to live in the city. Just as Pierre Boudoir, a French sociologist thinks that cultural capital can be converted into economic capital under certain conditions, and that it is institutionalized in the form of educational qualifications. At present, most of the migrant are eager for the city's highquality educational resources and bring their children to the city. As a result, the number of children who study in urban public schools is increasing. In 2011, migrant children attended about $79.2 \%$, an increase of $12.7 \%$ over 2010 . According to the state and the Reform Commission announced that as of February 2016, the state financial funds to protect the migrant children on compulsory education phase, their enrollment ratio have reached $90 \%$.

As a result, the great contrast between urban and rural education also brings great pressure and discomfort to the public schools and their teachers who accept the migrant children. First of all, because the migrant children receive the pre-school education, generally behind the urban children, who mean that when they enter the formal school system, there is a gap between urban children and urban children. Secondly, some students who transfer from schools for migrant workers' children, because of the differences in teaching content and teaching level, there is a certain difference in learning situation. Therefore, the differences between urban and rural education among children in the same school environment become more and more prominent, but the education differences cannot be offset, nor a "discriminatory" can be resolved, must take the difference of the compensation treatment can be solved.
Second is the existence of cultural differences. For the admission from all parts of the country migrant children's public schools, they are from different provinces and regions, cultural traditions, human geography, history, customs and so caused a lot of differences in the cultural background. These cultural differences are not only obvious, but also diverse: both urban and rural cultural differences, there are not only different regional culture, language, but also differences in customs and habits, which often affect the development of children's intelligence, and make them form a unique cognitive model and learning style. In the face of urban culture and education model, it is bound to encounter some discomfort or even conflict due to the heterogeneous culture or educational model, which put forward higher requirements for teacher and the school, how to bridge discomfort and make them achieve harmony and unity. As the American anthropologist Julian Steward (J H Steward) stressed in his book "cultural change theory": the diversity and individual of cultural elements must be faced in the development process, so as to achieve harmony and unity by consciously coordination and balance. As a result, public schools must consider the cultural background of each child's development, and recognize and respect the diversity of different students when dealing with the cultural differences between the migrant and urban children, to carry out the differential interaction, and create a multi-cultural campus atmosphere in the specific education and teaching activities.

\section{THE IMPLEMENTATION OF DIFFERENTIATED TEACHING}

Difference teaching began to become the educational concept that educational circles pay close attention to in the last century in 90s.Scholars Hua Guodong defined the difference teaching as "based on the students' differences, to meet the individual needs of students, so as to promote the students' fully developed on the basis of the original." Then, in the current public schools which accept the migrant children, the difference teaching is regarded as the essential component of the teaching and learning; teaching should start from the specific differences between urban and rural children, design teaching content, process and results, and promote the development of each child. That is, taking into account the disadvantaged subsidies, but also to meet the normal development of local children, and make the two in common development of interaction. As mentioned earlier, in the face of the cultural difference existence, face differences, understand the difference for schools and teachers, as a kind of effective teaching resources, the implementation of differentiated teaching, to truly realize the fairness in the education process, and effectively ensure the effective implementation of the educational opportunities of the migrant children under the guidance of the policy of the state. Therefore, in the face of the two major factors: educational differences and cultural differences must be carried out to treat differences based on equality, promote common development of migrant and city children. First of all, for the existence of educational differences, we should take "compensatory education" which is inclined to the migrant children". That is in the state oriented education policy migrant children enrollment opportunities can be 
guaranteed under the premise, as the provider and the allocation of public education resources, public schools and teachers not only have the obligation to ensure all students sharing educational resources and learning opportunities, and in the face of the additional education demand in disadvantaged students, should be provided compensatory education for their development. In fact, this is the "compensation principle" after the equality principle in Rawls's fair judgment, and to carry out compensatory education can effectively reduce the unfairness in the educational process. After entering into the city school, because of the difference of urban and rural education, there is a gap between the city and the rural learning, coupled with different education environment and teachers' teaching methods, the migrant children will inevitably lead to frustration. If these students are not provided additional education and help, it is easy to produce a series of problems, such as more academic failure, interpersonal maladjustment, abnormal behavior, and then gradually marginalized for the activities cannot effectively participate and integrate into school. This is not only contrary to the original intention of giving equal access to schools, but also do great harm to their physical and mental development. The public schools and their teachers should quickly establish a compensation education support system, and provide diversified compensation education support programs according to their different needs. Firstly, provide learning grants, such as flexible curriculum, individualized teaching and additional extracurricular guidance, to make them master relevant knowledge and value, cultivate their good learning habits and learning attitude, so as to keep up with the pace of normal teaching. Secondly, in view of the new environment caused by the adaptation, we should provide professional psychological health consulting services, and configure the corresponding auxiliary equipment to dispel their psychological shock and confusion. Thirdly, provide training, guidance and support for their parents, and help them form a joint education with schools in their children's education. Only facing and take targeted differences measures to help them to learn and adapt psychologically.

Secondly, in view of the existence of cultural differences, we should carry out the differential interaction between urban and rural children, and create a harmonious and symbiotic multicultural environment. Compared with the specific discipline learning, the campus is a big classroom in which all students to participate in the activities, all students will unconscionably participate, by virtue of its unique culture atmosphere, the humanistic spirit of the school, the students are being assimilated, shaped unknowingly. In public schools accepting the migrant children, geographical differences has brought about cultural differences, the entire campus cultural environment has become relatively complex and diverse. In the face of the existence of these cultural differences, we should first treat these cultural differences correctly, and analyze its effect in the construction of campus culture; At the same time, we should create a harmonious campus cultural environment, regard the regional differences as a kind of campus cultural resources, and give full play to their positive role in the construction of campus culture. The schools and teachers should carry out multicultural education; let them know that campus cultural diversity is beneficial, it is necessary to enhance the understanding and communication between urban and rural areas. The schools should propagate and introduce the characteristics of different regional cultures through different activities, to enhance students' understanding of different regional culture, and eliminate their cognitive barriers. Secondly, cultural exchanges between urban and rural children will be carried out to increase the interaction between different cultures. In the interaction process of heterogeneous culture, enhance the understanding between the urban and rural children, can make students of different cultures from different regions, the local customs and practices of customs and culture in his hometown and scenic spots, increase students' love and longing for all parts of the country, and mutual understanding, deepen the feelings in the understanding. Through these methods, students can be realized that each spiritual culture has its advantages and disadvantages, and every region's culture has a positive spirit. The school carry out consciously multicultural interaction, create a diverse campus culture atmosphere of harmonious co-existence, students can learn other regional culture spirit and excellent quality, so as to improve their overall quality.

\section{CONCLUSION}

Generally speaking, whether it is the national policy of "seeking common ground", to protect the urban and rural children in educational starting point fairness and equality; or the teaching level of school education, according to the educational difference and cultural differences, carry out differentiated teaching, to ensure the migrant children education fairness, all in order to achieve the final results of the education fair, to realize migrant children' education development.

\section{REFERENCES}

[1] Yu Jian: Investigation report on school-age children and juvenile enrollment in some parts of China. [J], education research, 1997 (09).

[2] Shi Zhongying: the policy meaning and connotation of equal educational opportunities. [J], Peking University education review, 2007,5(4):77-81.

[3] Michael Ruskin, Lin Zhen. "Political science" (Sixth Edition) [M], Beijing: Huaxia press, 2001, 384.

[4] Bao Yaming: cultural capital and social alchemy — Boudoir interview" [M], Shanghai people's press, 1997:192-194.

[5] Wu Jing: education changed a new world, [N], China Youth daily,[EB/OL].[2012-02-06]http://zqb.cyol.com/html/201202/06/nw.d110000zgqnb-20120206-6-01.htmhtml.

[6] Zhang Hongbo: cultural ecology theory and its implications for sustainable urban development in China. [J], modern urban studies, 2009(10): 85-90.

[7] Hua Guodong: difference teaching theory.[M], Beijing: Education Science Press, 2001:24 